\title{
Mucoid bone marrow without carcinoma deposits
}

\author{
M. A. Traill* \\ M.B., B.S. \\ Medical Officer, Pathology Department, Repatriation General Hospital, \\ Heidelberg, Victoria, Australia
}

Mucus production by adenocarcinomas is a common occurrence. Two cases are to be reported where mucus so produced by carcinoma in the retroperitoneal tissue may have collected in the bone marrow compartment without any evidence of direct cellular metastasis. In one case, it was observed during life.

\section{Case reports}

\section{Case 1}

A male born in 1903. He had a past history of duodenal ulceration.

In 1959, after a coronary occlusion, he complained of difficulty in swallowing food. A barium swallow showed narrowing and irregularity of the distal end of the oesophagus reaching just above the diaphragm. At oesophagoscopy a 3-cm length of yellow slough and hyperaemia was observed, and biopsy was considered to be highly suspicious of cancer. However, no firm diagnosis was made, and he was not followed up.

When seen in 1961, interest was confined to his cardiac state only. It would appear that he volunteered no gastro-intestinal symptoms.

In 1966 he complained of epigastric pain. A barium meal was not satisfactory technically, but it was thought that his duodenum did show much scarring. His haemoglobin concentration was $17 \cdot 7 \mathrm{~g} / 100 \mathrm{ml}$.

His final admission occurred in 1967. He noted more difficulty in swallowing. His haemoglobin concentration had fallen to $5 \cdot 2 \mathrm{~g} / 100 \mathrm{ml}$, and he had a $10 \%$ reticulocytosis. His serum iron was $60 \mu \mathrm{g} /$ $100 \mathrm{ml}$ and faecal occult blood was present. Bone marrow was aspirated from the posterior iliac crest, and revealed much mucinous material through the marrow clumps, which stained metachromatically with the Romanowsky stains (Fig. 1). No neoplastic cells were identified.

A barium meal showed rigidity of the lower twothirds of the oesophagus, and some irregularity of the lesser curve of the stomach, which was not narrowed.

* Present address: Pathology Centre, Mont Park, Victoria, Australia, 3085.

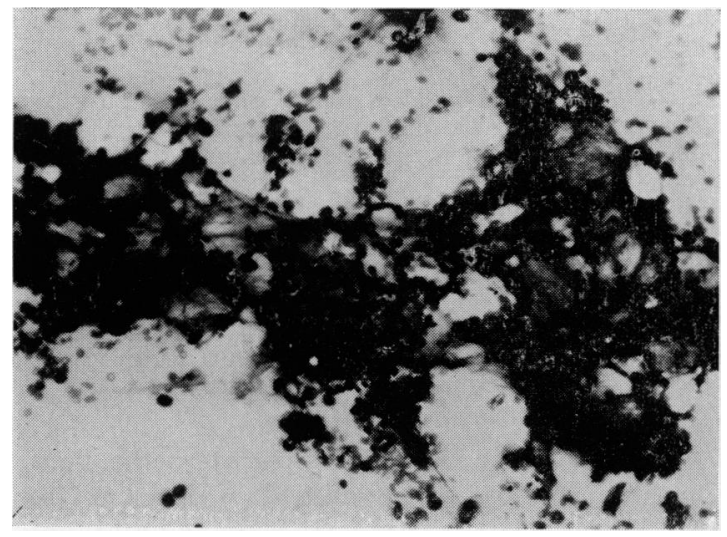

Fig. 1 A clump of marrow from the aspirate of Case 1. Metachromatic staining of the mucoid infiltrate reveals it clearly. Romanowsky stain, $\times 120$.

On oesophagoscopy, the appearances were of cancer, and a biopsy showed the presence of an adenocarcinoma. Thereafter his condition deteriorated, he developed ascites and died.

Necropsy revealed a stomach with walls of solid mucoid carcinoma, in most areas $2.5 \mathrm{~cm}$ thick. Extension had occurred up the oesophagus, to convert it to a rigid, thick walled tube, but with little narrowing. There was much peritoneal spread, particularly in the lymphatic channels, with retroperitoneal fibrosis and ureteric obstruction. No tumour deposits or cells could be identified in the marrow, either macroscopically or microscopically. There were virtually no areas of fat present, instead an infiltration by mucus (a picture similar to Fig. 2).

\section{Case 2}

A male born in 1888. In 1968 he complained that for 2-3 months he had noticed a pain in his chest after meals, which was relieved by vomiting. He had lost weight. 


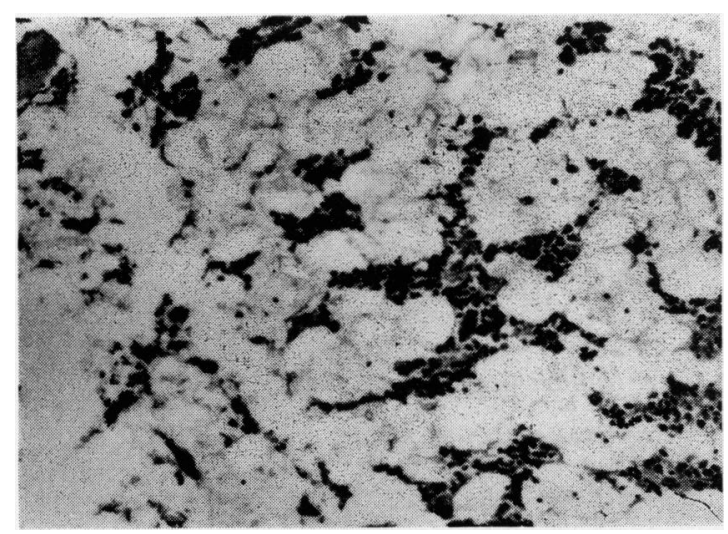

Fig. 2. A section of vertebral bone marrow from Case 2. Mucus secreting cells could not be identified even with the aid of stains for mucus. Alcian blue stain, $\times 120$.

A barium meal was difficult to perform because of his debility, and no gross abnormality was noted. His haemoglobin concentration was $12.9 \mathrm{~g} / 100 \mathrm{ml}$. Faecal occult blood was detected. His condition deteriorated rapidly, and his blood urea concentration rose. He died without further relevant investigations.

Necropsy. There were 2.6 litres of ascitic fluid. The stomach had a thickened wall especially posteriorly, caused by a mucus secreting infiltrating carcinoma. Carcinoma had spread into the peritoneum and produced adhesions which had partially obstructed the ascending colon, and produced retroperitoneal fibrosis with obstruction of the ureters.

The vertebral marrow showed no macroscopic or microscopic evidence of cancer cell metastasis there, but the fat had been replaced by mucus (Fig. 2).

\section{Discussion}

Both cases had a mucus-secreting infiltrating carcinoma of the stomach with retroperitoneal involvement. In the first case, it appears likely that the tumour had been present for 7 years, a remarkable survival for any form of therapy. The large quantity of mucus produced by the tumour deposits appears to be able to track to the marrow, and over a length of time, replace the fat deposits. Considering the gastric lesions, both patients appeared to be able to maintain their haemoglobin levels reasonably despite the marrow changes. With these tumours, gastric or oesophageal obstruction or radiological evidence of filling defects were not marked, so that the presence of mucus in the spinal or pelvic marrow may be of some diagnostic assistance in the investigation of gastric or retroperitoneal pathology.

\section{Acknowledgments}

I wish to thank the Chairman of the Repatriation Com mission for permission to publish this report, Mr W. Ruffnes for assistance with the photography, Miss $H$. Wischusen and Mr D. McKenzie for technical assistance.

\title{
Placenta praevia and ruptured exomphalos: a problem in diagnosis
}

\author{
Cyril S. Pallewela* \\ M.B., M.R.C.O.G. \\ Registrar, \\ City of London Maternity Hospital
}

THIS case is presented as a problem in diagnosis and management.

The occurrence of placenta praevia with exomphalos is extremely rare. On reviewing the literature as far back as 1885 no such case seems to have been reported. The incidence of exomphalos has been variously reported as 1 in 5000 to 1 in 11,000 live births and that of placenta praevia alone 1 in 200 . The incidence of foetal abnormality associated with placenta praevia is quoted by Macafee as $3.4 \%$. This, however, takes the form of spina bifida, hydrocephalus and anencephalus. As stated earlier, the incidence of a combination has not been worked out.

\footnotetext{
* Present address: St Albans City Hospital.
}

\section{Case report}

A young girl, Miss J.A., aged 20 years, unmarried, booked for her first pregnancy on 8 May 1967, following a period of amenorrhoea of 15 weeks.

On examination her general condition was satisfactory. The size of the uterus corresponded to dates.

Investigations: WR and GCFT negative; group $O$ Rhesus positive; haemoglobin, $81 \%$; blood pressure, 100/60; cardiovascular and respiratory systems, normal.

From about 30 weeks onwards the height of the fundus was noted to be smaller than the dates suggested. At the 35th week by dates the foetus was 